\title{
Editorial
}

\section{Immunology and Molecular Biology of Protozoan Infections}

\author{
Ali Ouaissi \\ INSERM, IRD UR008 “Pathogénie des Trypanosomatidés”, Centre IRD de Montpellier, 911 Avenue Agropolis, BP 64501, \\ 34394 Montpellier, France \\ Correspondence should be addressed to Ali Ouaissi, ali.ouaissi@montp.inserm.fr \\ Received 6 December 2007; Accepted 6 December 2007 \\ Copyright (C) 2007 Ali Ouaissi. This is an open access article distributed under the Creative Commons Attribution License, which \\ permits unrestricted use, distribution, and reproduction in any medium, provided the original work is properly cited.
}

\begin{abstract}
The protozoan parasites, which cause important diseases affecting million of people worldwide especially in the tropical and subtropical areas, are responsible for high mortality and morbidity. Most of these parasites are transmitted by insect vectors and invade a range of different tissues in their mammalian hosts. Prophylactic and therapeutic strategies are far from satisfactory. Indeed, although significant progress has been made in our understanding of the immune response to parasites, no definitive step has yet been successfully done in terms of operational vaccines against parasitic diseases. Moreover, some drugs are available, but there are concerns over their effectiveness, toxicity, and emergence of resistant strains.

An acquired immune response is the expected outcome of invasion by any living foreign organism, yet in many hosts the parasites are able to survive for long periods and most of the host-parasite systems explored demonstrated their own peculiarities to reach this equilibrium.

In this issue of the Journal of Biomedicine and Biotechnology, functional lessons learned from a number of parasitic models: (Malaria, leishmaniasis, Chagas'disease, and toxoplasmosis) have been gathered. Analysis of plasmodium falciparum parasitized red blood cells cytoadherence to host cell receptors, a key step in the progression of parasitic infection, revealed that in the case of pregnancy-associated malaria (PAM), P. falciparum isolates from infected pregnant women and children have distinct adhesive and antigenic properties from that of parasites causing cerebral malaria. This strengthened the possibility that antigens expressed by parasites causing PAM could be potential targets for vaccine development. Furthermore, recent advances in DNA vaccines against protozoan parasites especially Leishmania and Trypanosoma cruzi have been reviewed in this special issue. The parasite and their released products elicit a complex series
\end{abstract}

of cellular interactions leading to the activation/inhibition of the host immune system. This relies on ligand (s)-receptor (s) association among which CD40/CD40L costimulatory signaling, induction of immune cells such as dendritic cells, macrophages and $\mathrm{T}$ and $\mathrm{B}$ lymphocytes producing themselves various cytokines: IL-10, IL-12, IL-23, IL-27, IL-17, among others which create a microenvironment that may promote the development of defined Th cells. The balance between cytokine producing Th cells will determine the outcome of parasitic infection. This up-to-date information has been discussed in terms of physiological processes and therapeutic implications. The contributors convey both the state of the art and the direction of future studies in this particular area of research.

\section{ACKNOWLEDGMENTS}

As an Editor, I express my gratitude to the contributing authors as well as to the Editor-in-Chief, Dr. Abdelali Haoudi, for the opportunity provided by the Journal of Biomedicine and Biotechnology to present to the scientific community various facets of protozoan parasites-host interplay.

Ali Ouaissi 


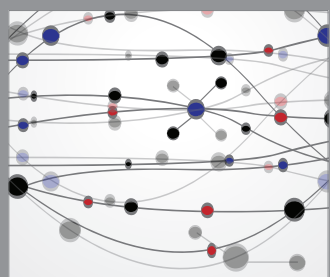

The Scientific World Journal
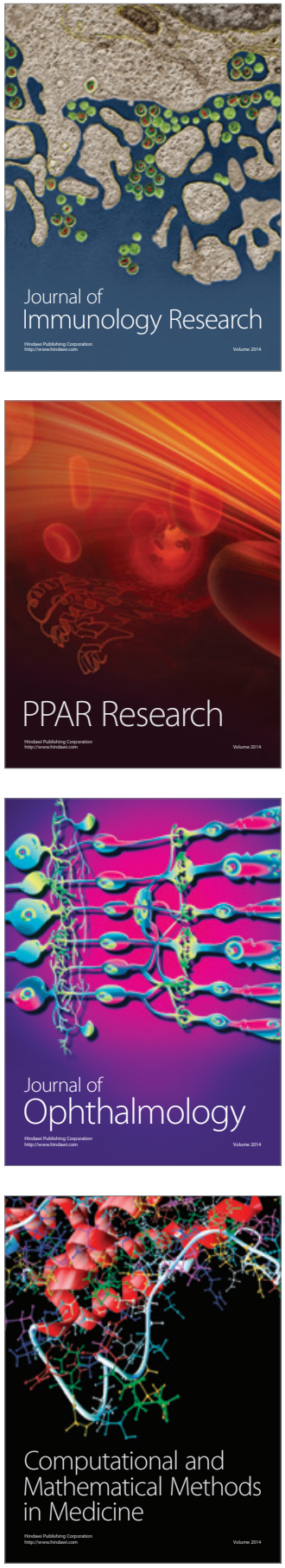

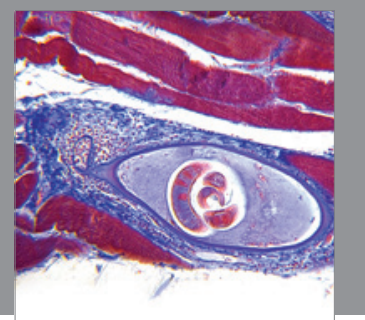

Gastroenterology

Research and Practice
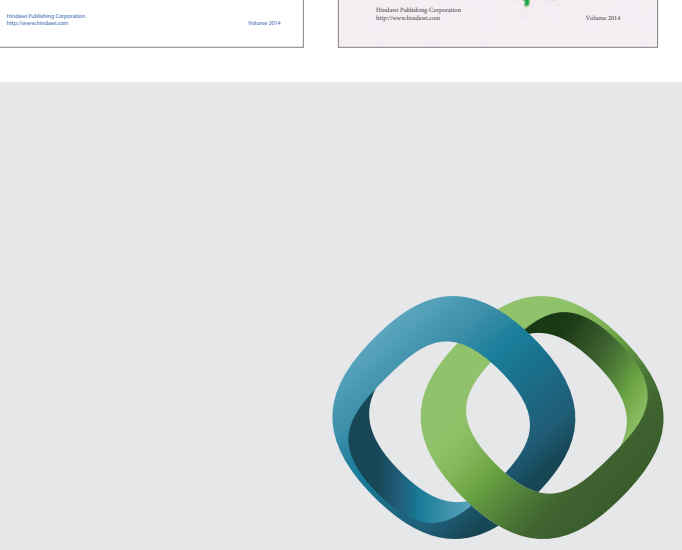

\section{Hindawi}

Submit your manuscripts at

http://www.hindawi.com
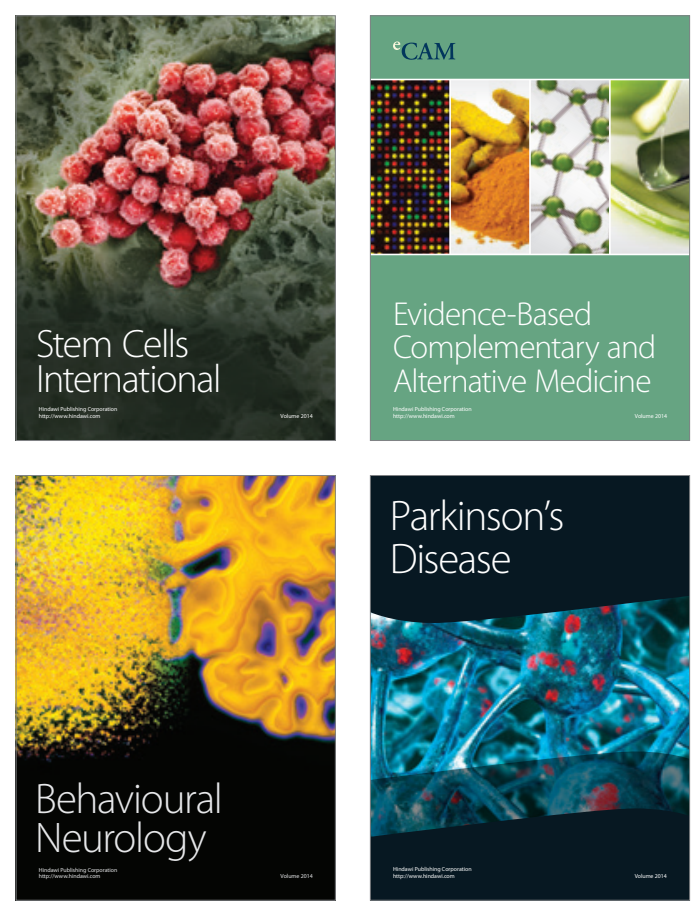

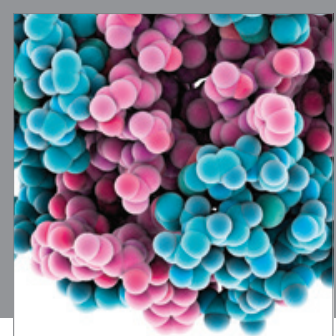

Journal of
Diabetes Research

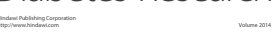

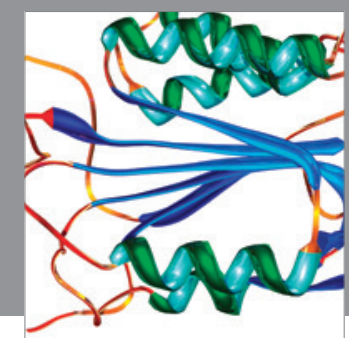

Disease Markers
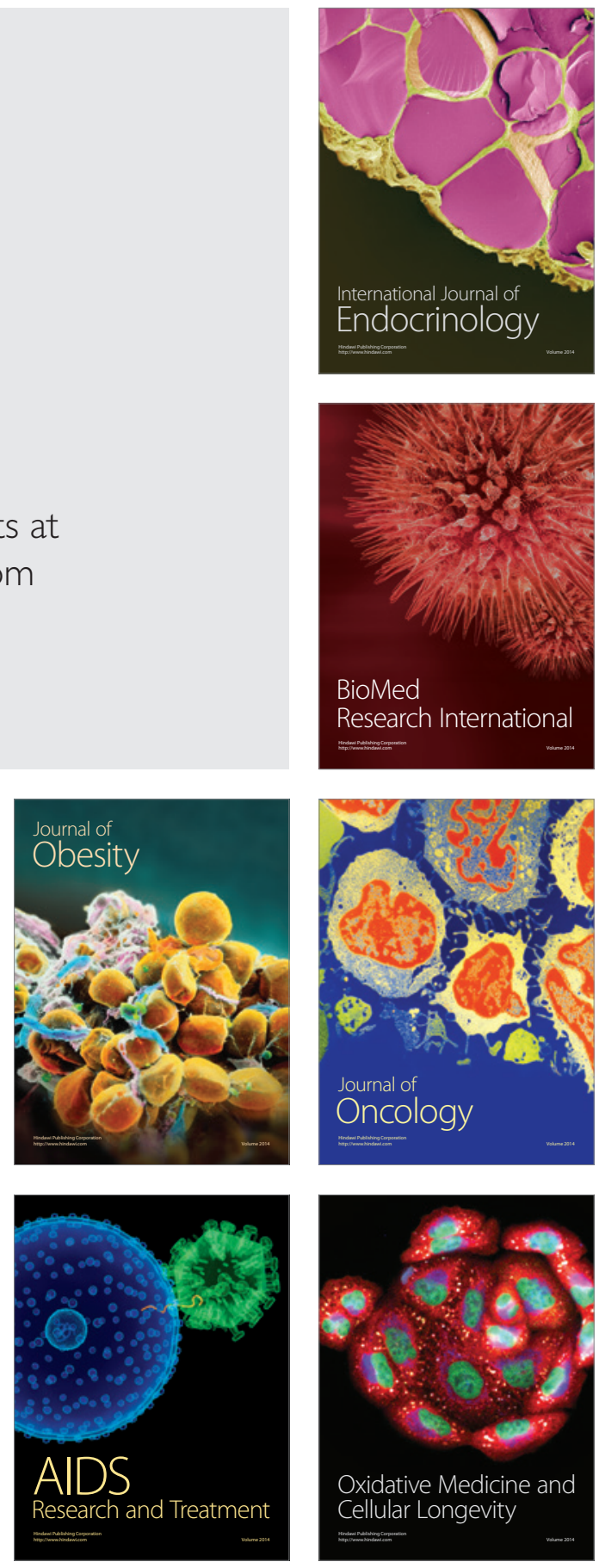